\title{
Study of Vapour Absorption System Using Various Working Fluids
}

\author{
Nisha Sen ${ }^{1}$, Dr. O. K. Singh ${ }^{2}$ \\ ${ }^{1}$ Indira Gandhi Delhi Technical University for Women, Kashmere gate, Delhi, India \\ ${ }^{2}$ Assistant Professor, Dept. of MAE, IGDTUW, Kashmere gate New Delhi, India
}

\begin{abstract}
Due to ever increasing global temperature the need of refrigeration system is increasing. Now a day's refrigeration consumes quit a large amount of energy. Our dependency on non renewable energy resources for electricity production there is need to develop a refrigeration system which is either independent of non renewable energy or requires a very little amount of the same. So this problem attracted the researcher towards development of the vapour absorption system, because it is environment and eco friendly and can use low grade energy such as solar energy, waste energy etc. besides of many advantages the absorption system has coefficient of performance less then unity. To be served by its advantages efficiently, in recent years, research has been devoted to improvement of the performance of vapour absorption system. In this paper a number of researches on working fluid are discussed.
\end{abstract}

Keywords: Ammonia-lithium nitrate $\left(\mathrm{NH}_{3}-\mathrm{LiNO}_{3}\right)$, Ammonia-sodium thiocyanate $\left(\mathrm{NH}_{3}-\mathrm{NaSCN}\right), \mathrm{COP}$.

\author{
Notations: \\ $\mathrm{COP}=$ coefficient of performance \\ $\mathrm{Q}=$ thermal energy \\ $\mathrm{m}=$ mass flow rate \\ $\varepsilon=$ ammonia mass fraction in solution \\ $\mathrm{T}=$ temperature \\ $\mathrm{h}=$ enthalpy \\ $\mathrm{P}=$ pressure \\ Subscript: \\ $\mathrm{e}=$ evaporator \\ $\mathrm{a}=$ absorber \\ $\mathrm{c}=$ condenser \\ $\mathrm{g}=$ generator
}

\section{Introduction}

The market is dominated by vapour compression system due to its high performance. Compression system requires mechanical energy and this is provided by electrical energy which is produced by burning of fossil fuels. So the consumption of conventional energy resources is very high and its limited availability reflected in rising price of electricity. In contrast vapour absorption system can use renewable energy resources which are available in abundance. Another major difference between compression and absorption system is the working fluid used. Mostly chlorofluorocarbons (CFC) are used by compression system and we know that halogens are the reason for depletion of ozone layers. The refrigerant used for the absorption system like ammonia, water etc. are very cheap and easily available. The restriction of the refrigerant in compression system again makes absorption system more superior.

Above reasons make vapour absorption system an economic option [1-4].

\subsection{Principle of Vapour Absorption System}

Vapour absorption system also known as heat operated system because it uses low grade thermal energy. Binary solution is used as a working fluid consists of refrigerant and absorbent. Refrigeration effect is produced by connecting two evacuated vessel fig.1 (a), left vessel containing refrigerant and right is containing solution (refrigerant + absorbent). Pressure is to reduce in left vessel when refrigerant vapour is absorbed by the solution in right vessel. The refrigeration accurse inside the left vessel due to vaporization of refrigerant its temperature reduces. At the same time inside the right vessel solution becomes more dilute because of increased amount of refrigerant by absorption. An absorption process is an exothermic process, so to maintain the absorption capability heat must be rejected to the surrounding.

Due to the saturation of the refrigerant the solution cannot continue with the absorption process, and then it becomes necessary to take out the refrigerant from the diluted solution. For this process heat is supplied to the right vessel Fig1 (b). The refrigerant vapour condenses by rejecting heat to the surrounding. By these processes, heat energy is used to produce refrigeration effect. This system is intermittent system as it produces refrigeration effect in one step during the entire process. 


\section{International Journal of Science and Research (IJSR) \\ ISSN (Online): 2319-7064}

Index Copernicus Value (2013): 6.14 | Impact Factor (2015): 6.391

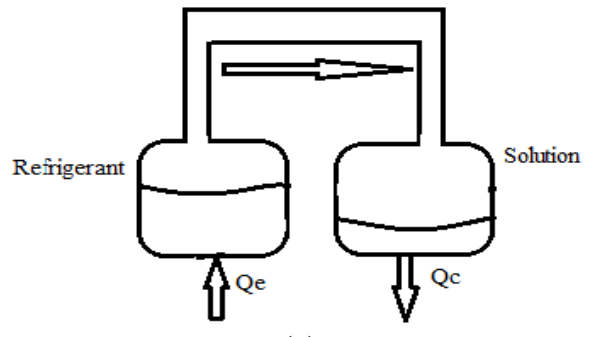

(a)

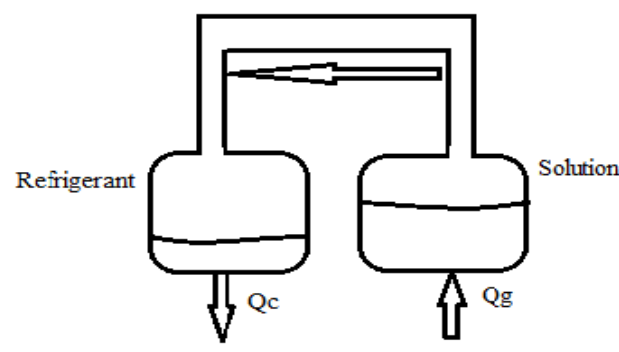

(b)

Fig.1 (a) cooling effect in right vessel due to the absorption process in right; (b) shows the regeneration process means separation of refrigerant from solution

Therefore to make the absorption refrigeration to be continuous, combine above two process fig 2 . The separation of refrigerant from the diluted solution occurs at higher pressure than absorption process, so to circulate the solution a pump is required. A coefficient of absorption system is obtained from:

$$
\mathrm{COP}=\frac{\text { cooling capacity }}{\text { heat input+pump work }}
$$

Work done by the pump is negligible as compared to the heat input for the generator because specific volume of the liquid is very small.

\section{Cycle Description}

Absorption system consists of main four parts:

- Generator

- Condenser

- Evaporator

- Absorber

- Pump

The strong solution made to pass through the heat exchanger from absorber to generator, stream (7). In generator heat is added to separate the refrigerant from the solution, the saturated vopur refrigerant then come out from the generator and go to the condenser, stream (1). After separation remaining solution is called weak solution. The refrigerant vapour passes to the condenser where heat is rejected by the refrigerant \& forms a liquid. After condensation liquid refrigerant is passed through the expansion valve to the evaporator, stream (3). In evaporator after providing Cooling of the space, liquid refrigerant gets evaporated at low pressure. After evaporation refrigerant goes to the absorber, stream (4) where vapour refrigerant losses its latent heat as it changes into liquid state by absorption by the absorbent.
Then strong solution pumped into the generator, stream (6). By preheating of the strong solution we improve the COP of the absorption system so heat exchanger is employed between generator and absorber. The hot weak solution coming from generator, stream (8) is passes through heat exchanger and at a same time strong solution is also made to pass through haet exchanger, by which preheating of the strong solution is possible, the process is repeated.

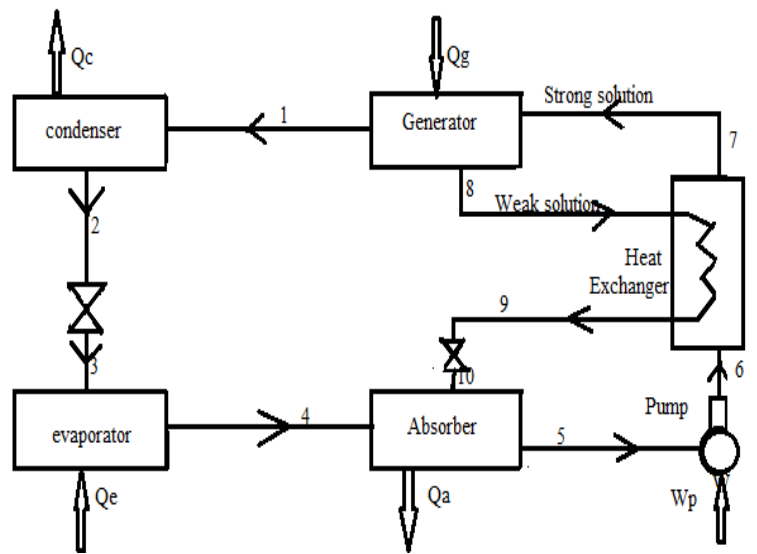

Figure 2: shows the complete schematic diagram of a vapour absorption refrigeration system

\section{Working Fluid}

The thermodynamics and chemical properties of the working fluid highly affect the performance of a vapour absorption system [5]. The desirable properties are as follows [6]:

- To make the strong solution rich in refrigerant the refrigerant should have more than Raoult's law solubility in the absorbent.To distill the pure refrigerant from generator, the difference in the normal boiling points of refrigerant and absorbent should be very large.

- Viscosity should be low so that pump work also get minimized.

- Should chemically and thermally stable

- Should have low freezing point

- Should not corrosive \& toxic

- Should not explosive

In literature many working fluid are described. Marcriss [7] provided a survey about the working fluid for the absorption system \&suggested around 40 refrigerant and 200 absorbent compounds. However the $\mathrm{NH}_{3}-\mathrm{H}_{2} \mathrm{O}$ (ammonia-water) and $\mathrm{LiBr}-\mathrm{H}_{2} \mathrm{O}$ are widely used as a working fluid. In $\mathrm{NH}_{3}-\mathrm{H}_{2} \mathrm{O}$ pair $\mathrm{NH}_{3}$ used as a refrigerant and in $\mathrm{LiBr}-\mathrm{H}_{2} \mathrm{O}$ pair water used as refrigerant.

\subsection{Advantages of using $\mathrm{NH}_{3}-\mathrm{H}_{2} \mathrm{O}$ as working pair:}

- For wide range of operating temperature \& pressure ammonia and water both are highly stable.

- For the efficient performance of the system latent heat of vaporization should be very high and $\mathrm{NH}_{3}$ has high latent heat of vaporization.

- Freezing point of $\mathrm{NH}_{3}$ is $-77.73^{\circ} \mathrm{C}$ so it can be used for low temperature application. 


\section{International Journal of Science and Research (IJSR) \\ ISSN (Online): 2319-7064}

Index Copernicus Value (2013): 6.14 | Impact Factor (2015): 6.391

Besides of the above advantages due to low difference between boiling point $\left(138^{\circ} \mathrm{C}\right)$ of ammonia and water installation of rectifier and analyzer becomes necessary. If rectifier and analyzer are not installed water vapour comes out with the distilled ammonia from generator which accumulated in evaporator and offset the system performance.

In this research $\mathrm{NH}_{3}-\mathrm{H}_{2} \mathrm{O}$ and possible alternative of refrigerant/absorbent pair such as ammonia-lithium nitrate and ammonia-sodium thiocyanate are compared. The basis of the comparison is COP and circulation ratio (f) of the system as function of generator, evaporator, and condenser and absorber temperature.

\subsection{For the current study following assumptions are made}

- Refrigerant vapour contains $100 \%$ ammonia

- Steady state and steady flow

- No pressure drop due to friction

- Pumping is isentropic

$$
\mathrm{COP}=\frac{Q e}{Q g+W r}
$$

The thermodynamic analysis of absorption system based on following three equations which can be applied at each component:

- Mass balance

$$
\sum m=0
$$

- Martial balance

$$
\sum m x=0
$$

- Energy balance

$$
\sum Q+\sum m h=0
$$

\section{Circulation ratio (f):}

It is defined by the quantity of rich solution handled by pump per unit mass of the vapour distilled.

$$
\mathrm{f}=\frac{\mathrm{mg}}{\mathrm{m} I}
$$

Energy balance for generator, evaporator, condenser and absorber and pump work yield:

- $\mathrm{Q}_{\mathrm{g}}=\mathrm{m}_{1} \mathrm{~h}_{1}+\mathrm{m}_{8} \mathrm{~h}_{8}-\mathrm{m}_{7} \mathrm{~h}_{7}$

- $\mathrm{Q}_{\mathrm{e}}=\mathrm{m}_{1}\left(\mathrm{~h}_{4}-\mathrm{h}_{3}\right)$

- $\mathrm{Q}_{\mathrm{c}}=\mathrm{m}_{1}\left(\mathrm{~h}_{1}-\mathrm{h}_{2}\right)$

- $\mathrm{Q}_{\mathrm{a}}=\mathrm{m}_{4} \mathrm{~h}_{4}+\mathrm{m}_{10} \mathrm{~h}_{10}-\mathrm{m}_{5} \mathrm{~h}_{5}$

- $\mathrm{Wp}=\left(\mathrm{P}_{6}-\mathrm{P}_{5}\right) \mathrm{v}_{6}$

To calculate the system performance the above equations can be solved if generator, evaporator, condenser, absorber temperature and the refrigerant mass flow rate or required refrigerant load are given.

\section{Comparison of Absorption Cycle Using Different Working Fluid}

The comparison of COP values against generator temperature for $\mathrm{NH}_{3}-\mathrm{H}_{2} \mathrm{O}, \mathrm{NH}_{3}-\mathrm{LiNO}_{3}$, and $\mathrm{NH} 3-\mathrm{NaSCN}$ has shown in fig. 3. It has been found that with generator temperature COP of the system increase and after reaching an optimal value it starts decreasing. This happens due to presence of degree of irreversibility which increases with generator temperature. We also know that there is also a optimal lower limit of temperature below which cycle cannot be operated. For $\mathrm{NH}_{3-}$ $\mathrm{LiNO}_{3}$ this lower limit of operating generator temperature is below than other two cycles. This is very important feature for using solar energy with flat plate are generally below $80^{\circ} \mathrm{C}$. It is noticeable from fig. 3 that $\mathrm{NH} 3-\mathrm{NaSCN}$ gives the highest COP at generator temperature higher than $80^{\circ} \mathrm{C}$, and $\mathrm{NH}_{3}-\mathrm{H}_{2} \mathrm{O}$ has the lowest COP. At low generator temperature $\mathrm{NH}_{3}-\mathrm{LiNO}_{3}$ cycle gives the best performance.

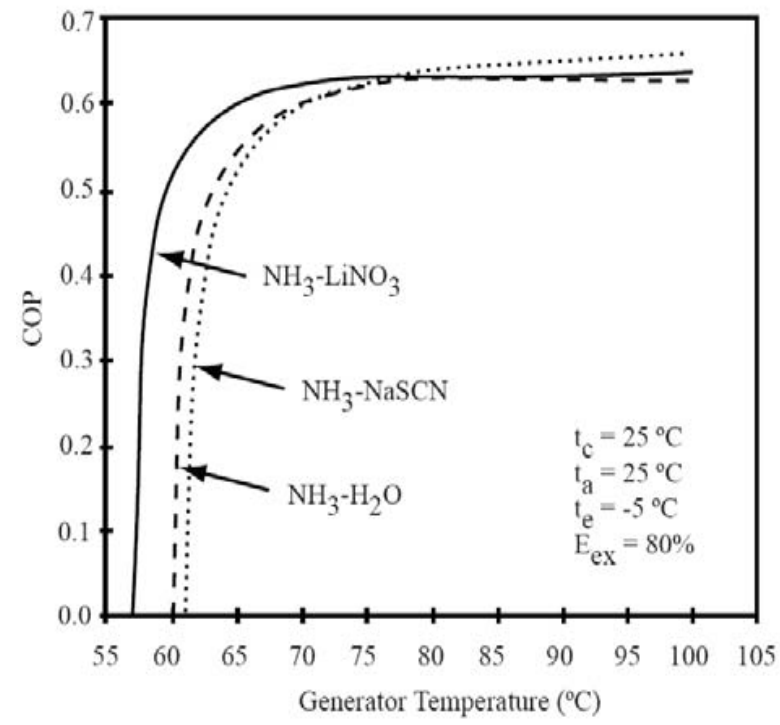

Figure 3: Comparison of the effect of COP values on generator temperatures [8]

In fig.4 comparison of circulation ratio against generator temperature has shown. Circulation ratio increases drastically if generator temperature tends to its lower limit. High circulation ratio means either the pump needs to run faster or mare powerful is required. So it is quit that due to clear that COP of the system will decrease because pump work increases with circulation ratio. From experiment for NH3$\mathrm{NaSCN}$ cycle higher circulation ratio has found than $\mathrm{NH}_{3}$ $\mathrm{H}_{2} \mathrm{O}, \mathrm{NH}_{3}-\mathrm{LiNO}_{3}$. So it's clear that for NH3-NaSCN cycle more powerful pump is required.

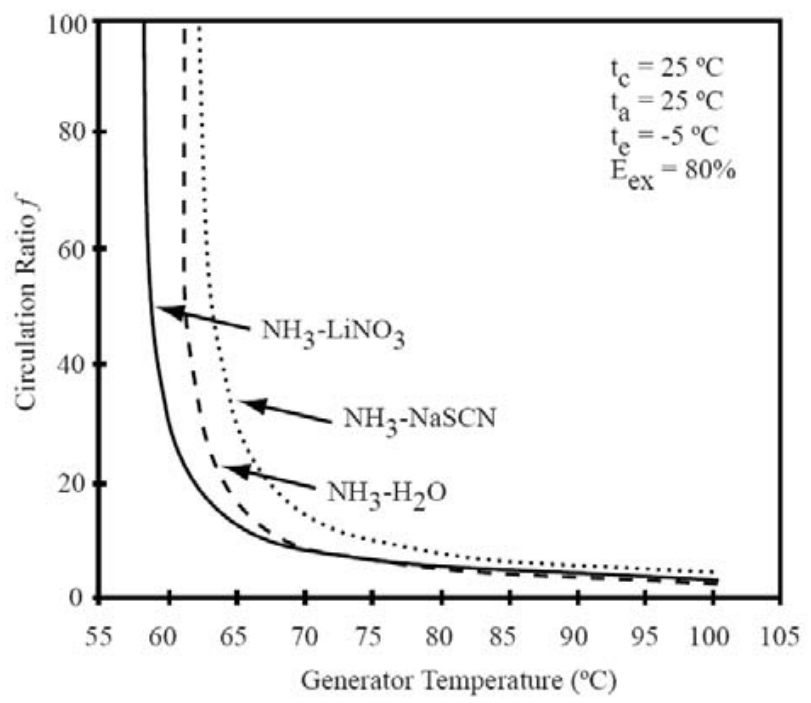

Figure 4: Comparison of the effect of circulation ratio values on generator temperatures [8] 


\section{International Journal of Science and Research (IJSR) \\ ISSN (Online): 2319-7064}

Index Copernicus Value (2013): 6.14 | Impact Factor (2015): 6.391

The comparison of the COP of the system varies with the evaporator temperature has shown in fig. 5. The COP of the system increases with evaporator temperature. Below the zero evaporator temperature $\mathrm{NH}_{3}-\mathrm{H}_{2} \mathrm{O}$ has lowest system performance but it has better performance than $\mathrm{NH}_{3}-\mathrm{LiNO}_{3}$ at higher evaporator temperature. From fig.5 it is clear that NH3-NaSCN has better performance at below zero evaporator temperature.

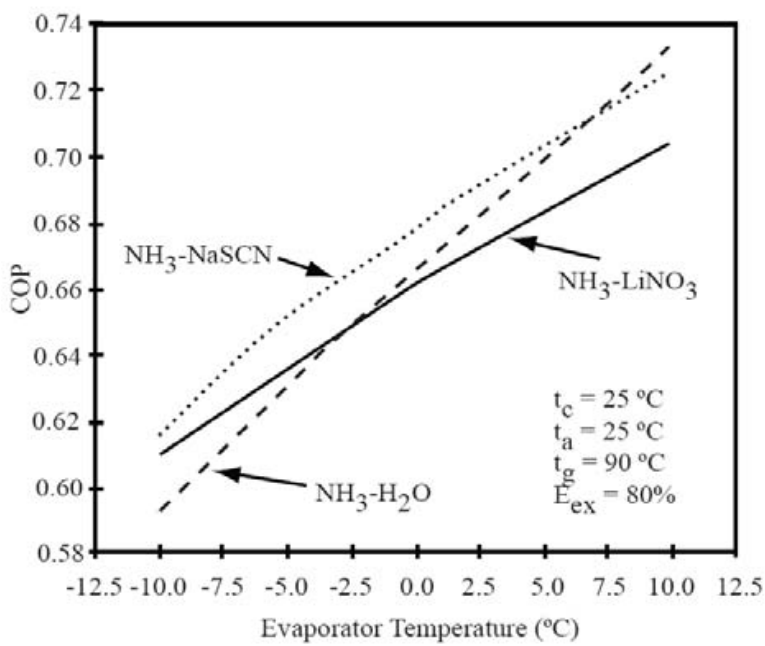

Figure 5: Comparison of the effect of COP values on evaporator temperatures [8]

The circulation ratio plotted against evaporator temperature in fig.6. From the fig it is very clear that NH3-NaSCN system has higher circulation ratio.

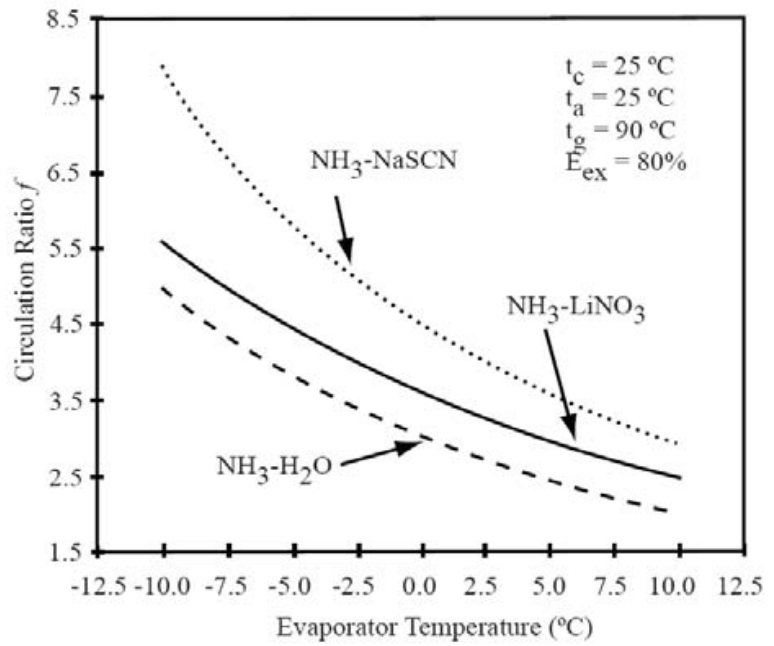

Figure 6: Comparison of the effect of circulation ratio values on evaporator temperatures [8]

We already know that with increasing temperature of condenser refrigeration effect decreases. From fig. 7 it is clearly visible that COP of the three system decreases with increasing temperature of condenser. But for the same temperature range $\mathrm{NH} 3-\mathrm{NaSCN}$ andNH${ }_{3}-\mathrm{LiNO}_{3}$ has better performance than $\mathrm{NH}_{3}-\mathrm{H}_{2} \mathrm{O}$. At low condenser temperature $\mathrm{NH} 3-\mathrm{NaSCN}$ has better performance while at high condenser temperature $\mathrm{NH}_{3}-\mathrm{LiNO}_{3}$ has the better performance. In fig. 8 circulation ratio $\mathrm{v} / \mathrm{s}$ condenser temperature has been plotted and again $\mathrm{NH} 3-\mathrm{NaSCN}$ has higher circulation ratio. From fig.9 it is clear that the effect of condenser temperature and absorber temperature are similar. Generally the temperature level remains same for both the condenser and absorber. The comparison between the $\mathrm{NH}_{3}-\mathrm{H}_{2} \mathrm{O}, \mathrm{NH}_{3}-\mathrm{LiNO}_{3}$ and $\mathrm{NH} 3-$ $\mathrm{NaSCN}$ cycle on the basis of circulation ratio $\mathrm{v} / \mathrm{s}$ absorber temperature has been shown in fig. 9 .

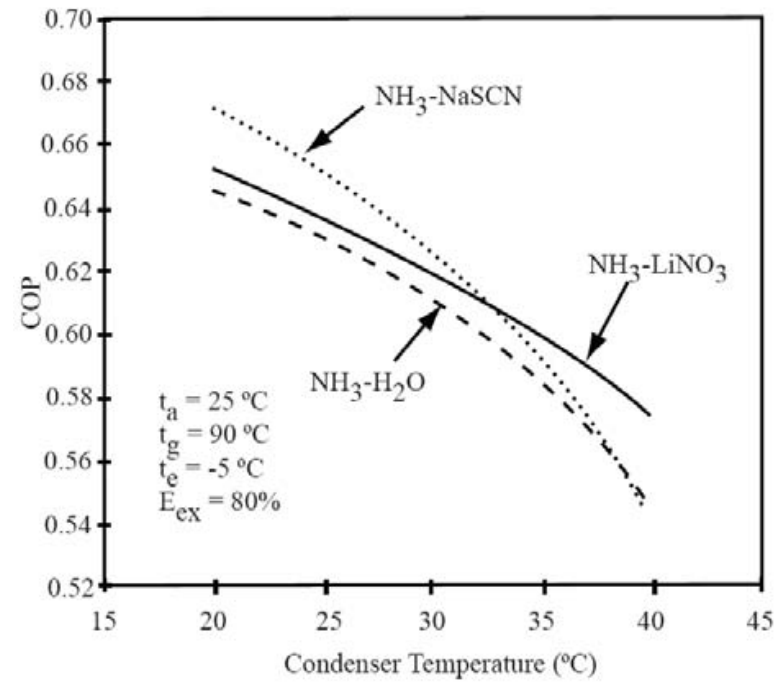

Figure 7: Comparison of the effect of COP values on condenser temperatures [8]

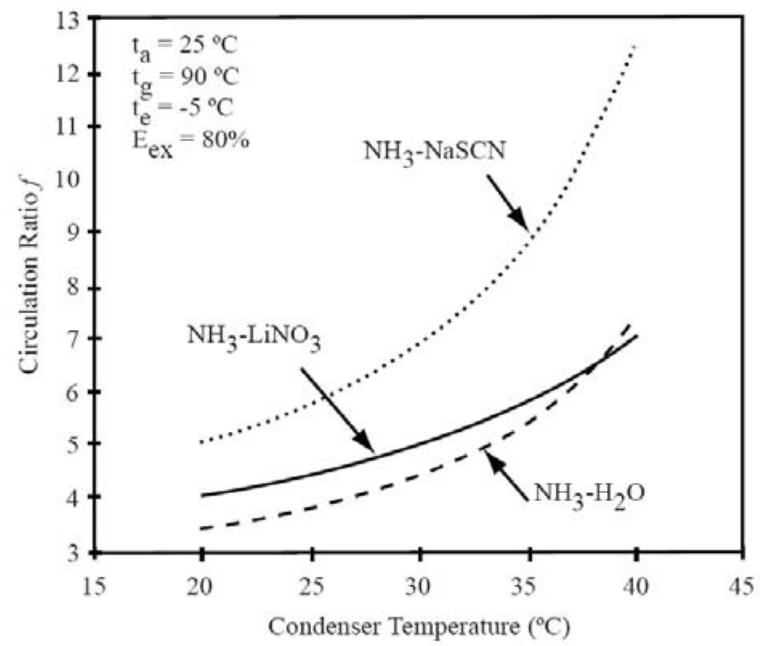

Figure 8: Comparison of the effect of circulation ratio values on condenser temperatures [8]

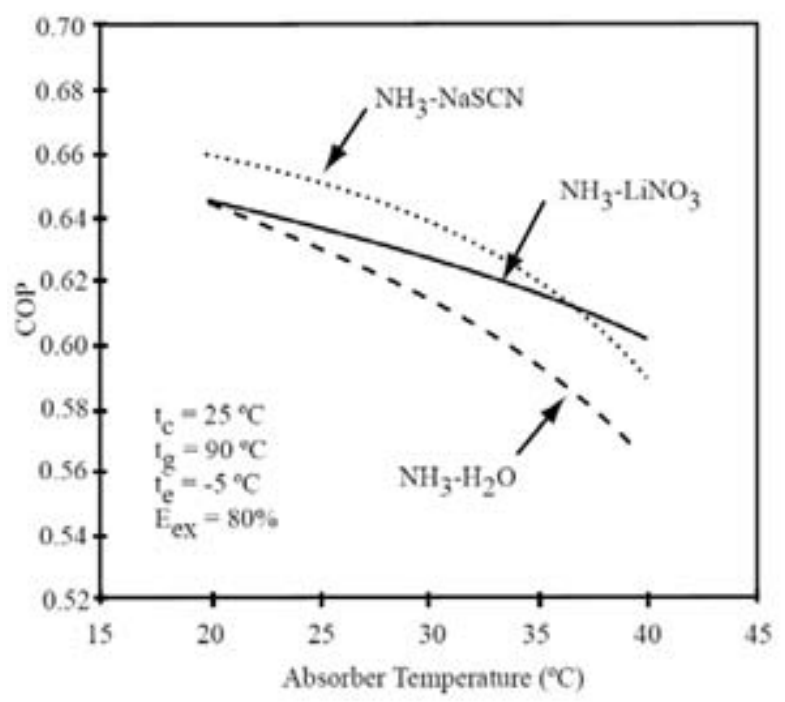

Figure 9: Comparison of the effect of COP values on absorber temperatures [8] 


\section{International Journal of Science and Research (IJSR) \\ ISSN (Online): 2319-7064}

Index Copernicus Value (2013): 6.14 | Impact Factor (2015): 6.391

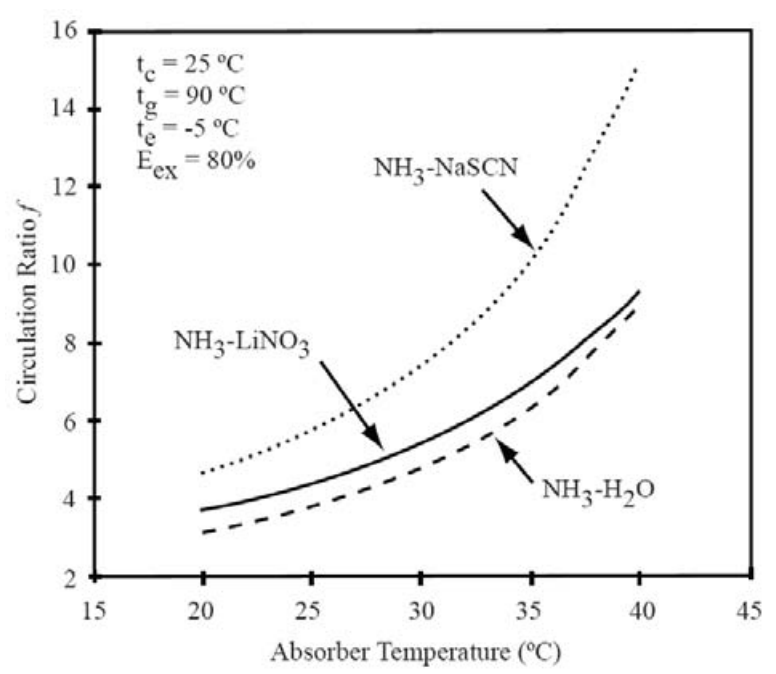

Figure 10: Comparison of the effect of circulation ratio values on absorber temperatures [8]

\section{Conclusion}

In the recent year's researcher's attention have been caught by absorption system due to its capability of using nonconventional energy resources. To improve its performance several efforts are being made to develop alternative refrigerant-absorbent pair. After studying three working pair name ammonia-water, ammonia-lithium nitrate and ammonia-sodium thiocyanate following conclusions are made:

1) Ammonia-water pair suitable where below $0^{\circ} \mathrm{C}$ temperature is required.

2) To get better performance of $\mathrm{NH}_{3}-\mathrm{H}_{2} \mathrm{O}$ analyzer and rectifier is necessary, but by using alternative like $\mathrm{NH}_{3}$ $\mathrm{LiNO}_{3}$ and $\mathrm{NH}_{3}-\mathrm{NaSCN}$ there necessity can be omitted.

3) The performance graph of these cycles against various operating temperature shows that the performance of NH3$\mathrm{NaSCN}$ and $\mathrm{NH}_{3}-\mathrm{LiNO}_{3}$ cycle are better than $\mathrm{NH}_{3}-\mathrm{H}_{2} \mathrm{O}$.

4)Due to possibility of crystallization of $\mathrm{NH} 3-\mathrm{NaSCN}$, it cannot be operated at evaporator temperature below $-10^{\circ} \mathrm{C}$.

5)It was observed that at low generator temperature $\mathrm{NH}_{3}$ $\mathrm{LiNO}_{3}$ gives better performance than other two cycles, so if the low temperature heat source is used it is advisable to use $\mathrm{NH}_{3}-\mathrm{LiNO}_{3}$.

\section{References}

[1] Eames I. W. Aphornratana, S. and Sun, Da-Wen, "Heat Recovery System \& CHP", 1995, 15, 711-721.

[2] Eames, Sun, Da-Wen, I. W. International journal of energy research 1996, 20, 871-885.

[3] Sun, Da-Wen, Energy, 1996, 21(10), 919-929.

[4] Sun, Da-Wen, Energy Sources, 1997, 19(4), 349-367.

[5] Perez-Blanco H. "Absorption heat pump performance for different types of solution". Int J Ref 1984; 7(2):115-22.

[6] C P Arora "Refrigeration and Air Conditioning". McGraw-Hill publication Second Edison. 2000, 1981, 427-437.

[7] Marcriss RA, Gutraj JM, Zawacki TS. Absorption fluid data survey: final report on worldwide data, ORLN/sub/8447989/3, Inst. Gas Tech., 1988.
[8] Da-Wen, Sun "Comparison ofthe Performance of $\mathrm{NH}_{3}$ $\mathrm{H}_{2} \mathrm{O}, \quad \mathrm{NH}_{3}-\mathrm{LiNO}_{3}$ and $\mathrm{NH} 3-\mathrm{NaSCN}$ Absorption Refrigeration System". PII: S0196-8904(97)00027-7.

[9] Z. Crepinsek, D. Goricanec, J. Krope "Comparison of the performances of absorption refrigeration cycles" Smetanova ul. 17, 2000 Maribor,SLOVENIA.

[10] Satish Raghuvanshi, Govind Maheshwari "Analysis of Ammonia -Water (NH3-H2O) Vapor Absorption Refrigeration System based on First Law of Thermodynamics" International Journal of Scientific \& Engineering Research Volume 2, Issue 8, August-2011 1 ISSN 2229-5518.

[11] Micallef,D. \& Micallef, C. "Mathematical Model Of A Vapour Absorption Refrigeration Unit". Int $\mathrm{j}$ simul model 9(2010)2,86-97 ISSN 1726-4529.

[12] Sachin Kaushik, Dr. S. Singh "Thermodynamic Analysis of Vapor Absorption Refrigeration System and Calculation of COP” IJRASET Vol. 2 Issue II, February 2014 ISSN: 2321-9653

\section{Author Profile}

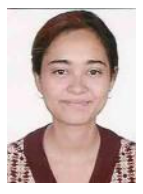

Nisha sen has received the B.Tech degree in Mechanical from Dr. K. N Modi Institute of Engineering and Technology in 2013, now pursuing M.Tech in Mechanical \& Automation Engineering from Indira Gandhi Delhi Technical University for

Women.

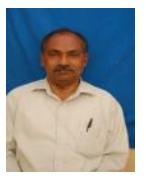

Dr. O. K. Singh has received his Ph.D. degree from IIT, Delhi for his research on Thermal Power Plants. He did his M.Tech. in Mechanical Engineering with specialization in Thermal Sciences with First Class (Honours) from Aligarh Muslim University (awarded Gold Medal for securing First Position), Graduation Certificate in Marine Engineering with First Class with Distinction from Directorate of Marine Engineering Training (presently known as Marine Engineering \& Research Institute), Bombay and B.Sc. Engineering (Mechanical) with First Class (Honours) from Regional Engineering College (presently known as National Institute of Technology), Calicut. He has about 13 years of teaching experience and serving in IGIT/IGDTUW since August, 2005. He has also served as a Marine Engineer in the past. He has contributed 8 research papers to the international journals of high repute. He is a life member of Indian Society for Technical Education. 